\title{
The Morphology of Bacillus cereus Bacteriophages
}

\author{
By I. M. DAWSON AND ELINOR SMILLIE \\ Department of Chemistry, University of Glasgow \\ AND J. R. NORRIS \\ Department of Bacteriology, University of Glasgow
}

(Received 16 September 1961)

\section{SUMMARY}

The 'negative contrast method' was used to study by electron microscopy four previously described Bacillus cereus bacteriophages. The main features of the structure of these phages are described and the observations correlated with similar work on phages associated with other genera.

\section{INTRODUCTION}

The application of the 'negative contrast' technique to the electron microscopy of phage particles by Brenner et al. (1959) and its use in the examination of a variety of different phages by Bradley \& Kay (1960) considerably extended our knowledge about the fine structure of phage particles. Observations made by using this technique have so far been concerned with phages of a small number of bacterial genera and there is a need for information relating to other types. Little is known about the morphology of the phages of aerobic spore-forming bacteria and only one electron micrograph showing a phage associated with protein crystal-forming Bacillus cereus strains appears to have been published, namely, a shadowed preparation showing the gross morphology (Afrikian, 1960). Roslycky \& Hannay (1961) in a brief note referred to a phage derived from 'Fowler's bacillus', which closely resembles B. cereus, stating that it has 'heads approximately $60 \times 60 \mathrm{~m} \mu$ and tails $200 \mathrm{~m} \mu$ in length'. The present communication records observations made when the phosphotungstate negative contrast technique was applied to the study of four phages isolated from $B$. cereus and from protein crystal-forming bacteria related to B. cereus (Norris, 1961).

\section{METHODS}

Bacteriophages. Phages A and B were isolated from Bacillus entomocidus var. entomocidus, phage $\mathrm{C}$ from $B$. entomocidus var. subtoxicus and phage $\mathrm{D}$ from $B$. cereus strain 826. The details of these bacterial strains and of the methods of isolation and propagation of the phages were described by Norris (1961).

Preparation of specimens for electron microscopy. Phages for electron microscopy were propagated on cultures of the appropriate bacteria grown on the surface of $1 \%(w / v)$ agar containing $1 \%(w / v)$ peptone in Petri dishes. Two drops of sterile filtered stock suspension of phage in nutrient broth containing about $10^{8}$ infective units $/ \mathrm{ml}$. were spread over the dry surface of plates previously inoculated with the propagating bacterium by flooding with an overnight broth culture. After incuba- 
tion at $30^{\circ}$ overnight each plate was flooded with $2 \mathrm{ml}$. of a $2 \%(\mathrm{w} / \mathrm{v})$ solution of ammonium acetate in distilled water and the areas which showed confluent phage lysis were gently rubbed with a smooth glass rod. The liquid was removed with a Pasteur pipette and the yield from similar plates pooled. The resulting suspension was centrifuged at $2000 \mathrm{rev} . / \mathrm{min}$. for $10 \mathrm{~min}$. to deposit bacteria and the supernatant phage suspension was used for electron microscopy with as little delay as possible. Potassium phosphotungstate was prepared from a $2 \%(w / v)$ solution of phosphotungstic acid in distilled water. Undissolved material was spun down and the solution adjusted to $\mathrm{pH} 7 \cdot 4$ by dropwise addition of $40 \%(\mathrm{w} / \mathrm{v}) \mathrm{KOH}$ solution. Phage suspension and potassium phosphotungstate solution were mixed in equal volumes and the mixture sprayed by an 'atomizer' spray on to specimen grids previously coated with carbon films and washed free from grease. The prepared specimens were studied immediately in the Siemens electron microscope 1 at a magnification of $\times 40,000$.

\section{RESULTS}

The general features of the preparations resembled those described by Bradley \& Kay (1960). The phage particles appeared as electron-transparent objects surrounded by an electron-dense background of phosphotungstate and showed the usual differentiation into head and tail components. The preparations consisted of mixtures of active and discharged phage particles, the empty head membranes of the latter being easily distinguished from the electron-opaque deoxyribonucleic acid (DNA)-filled heads of the former (Pl. 1, figs. 1-4).

The four phages are remarkably similar in appearance. The head shows in each case a hexagonal outline, the diameter usually a little greater than the apex to tail dimension. It is not possible to determine the three-dimensional shape of the heads from pictures of this kind, the choice apparently lying between an octahedron and an icosahedron (see Bradley \& Kay, 1960; Horne, Brenner, Waterson \& Wildy, 1959). Occasional heads show signs of internal membranous structures which may possibly be associated with the mechanism for DNA ejection. The tails are relatively long and flexuous and sometimes appear hollow when attached to empty heads. Terminal knobs of indefinite shape are often seen with each of the phages. Contractile tail sheaths were not noted and there was no clear indication of fine structure in the tails or in the head membranes. These phages appear to fall into the morphological group 2 of Bradley \& Kay (1960). Table 1 shows the dimensions of the four phages.

Table 1. Dimensions of four Bacillus cereus phages. Phosphotungstate preparations

\begin{tabular}{|c|c|c|c|}
\hline Phage & Head (A.)* & Tail (A.) $\dagger$ & Illustration \\
\hline $\begin{array}{l}\mathbf{A} \\
\mathbf{B}\end{array}$ & $\begin{array}{l}640 \pm 56 \times 640 \pm 40 \\
630+30 \times 680+30\end{array}$ & $\begin{array}{l}2000 \pm 20 \times 95 \pm 10 \\
2000+50 \times 80+10\end{array}$ & Pl. 1, fig. 1 \\
\hline C & $620 \pm 30 \times 590 \pm 40$ & $2000+50 \times 75+5$ & Pl. 1, fig. 3 \\
\hline D & $620 \pm 40 \times 580 \pm 30$ & $2155 \pm 90 \times 75 \pm 5$ & Pl. 1, fig. 4 \\
\hline
\end{tabular}

* The apex-tail dimension is given first then the width.

$\dagger$ The length is given first then the width. 


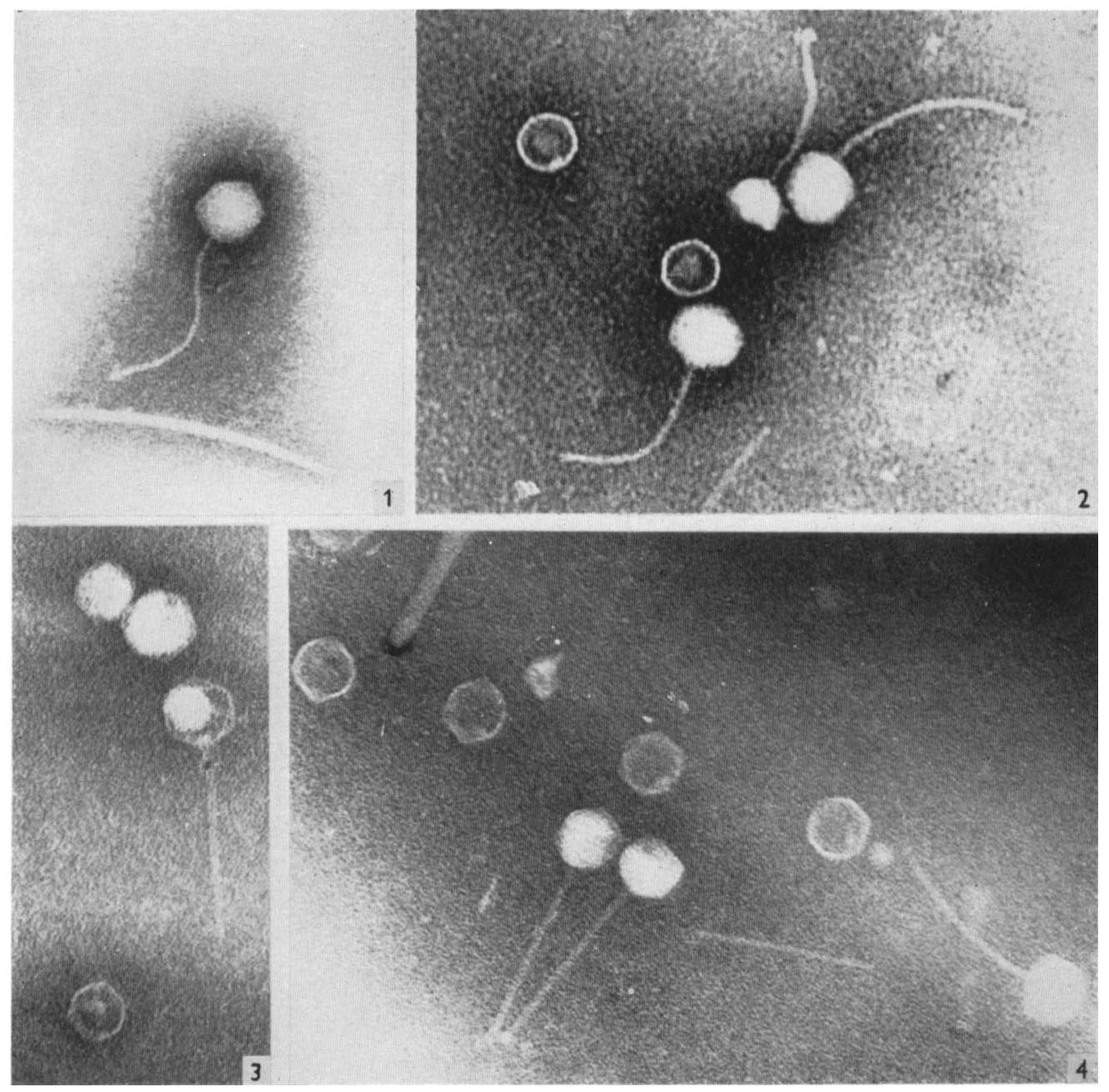




\section{DISCUSSION}

Little is known about the general characteristics of the phages of the Bacillus cereus group and virtually nothing about their morphology. The results presented here are primarily of morphological interest and demonstrate that these phages have the 'conventional' structure associated with phages of several other genera. The similarity between these Bacillus cereus phages and some of the phages of Pseudomonas, Staphylococcus, Escherichia coli and Salmonella typhi described by Bradley \& Kay (1960) is striking and emphasizes that a study of morphology is unlikely to be of great assistance in developing a system of classification of bacteriophages. The absence of contractile sheaths in these phages would appear to preclude the DNA ejection system which operates in some of the coli-typhoid phages. An alternative as yet unknown mechanism, possibly associated with the membrane structures sometimes seen inside the phage heads, must be assumed.

One of us (J.R.N.) is indebted to the Agricultural Research Council for a grant in aid of this work.

\section{REFERENCES}

Afrikian, E. G. (1960). Causal agents of bacterial diseases of the silkworm and the use of antibiotics in their control. J. insect Path. 2, 299.

BradLEY, D. E. \& KAY, D. (1960). The fine structure of bacteriophages. J. gen. Microbiol. 23, 553.

Brenner, S., Streisinger, G., Horne, R. W., Champe, S. P., Barnett, L., Benzer, S. \& REES, M. W. (1959). Structural components of bacteriophage. J. mol. Biol. 1, 281.

Horne, R. W., Brenner, S., Waterson, A. P. \& Wildy, P. (1959). The icosahedral form of an adenovirus. J. mol. Biol. 1,84 .

Norris, J. R. (1961). Bacteriophages of Bacillus cereus and of crystal-forming insect pathogens related to Bacillus cereus. J. gen. Microbiol. 26, 167.

RosLycky, E. B. \& HanNay, C. L. (1961). Lysogeny of the parasporal body forming Fowler's Bacillus. Bact. Proc. V70.

\section{EXPLANATION OF PLATE}

Plate 1

Electron micrographs of Bacillus cereus bacteriophages. Phosphotungstate preparations.

Fig. 1. Phage A. $\times 122,000$.

Fig. 2. Phage $B . \times 120,000$.

Fig. 3. Phage C. $\times 123,000$.

Fig. 4. Phage D. $\times 120,000$. 